\title{
As contribuições relativas ao uso de eventos/fóruns para constituição de comunidades de práticas e expressão da inteligência coletiva: o caso do Bibliocontas
}

Helena de Fátima Nunes Silva

Doutora em Engenharia de Produção pela Universidade Federal de Santa Catarina (2004). Professora da Universidade Federal do Paraná, Coordenadora do curso de graduação em Gestão da Informação.

Aline Elis Arboit

Doutoranda em Ciência da Informação na Universidade Estadual Paulista (UNESP). Bibliotecária do Tribunal de Contas do Estado do Paraná, desde 2006.

Andrea Karina Garcia

Mestre pela Universidade Federal do Paraná, Bacharel e licenciada em História pela Universidade Federal do Paraná

\section{Camila Fernanda Rigoni}

\begin{abstract}
Mestre pela Universidade Federal do Paraná,. Bacharel em Administração de Empresas pela Universidade Federal do Paraná. Analista de Inteligência de Mercado da Botica Comercial Farmacêutica Ltda.
\end{abstract}

Reflete sobre as Comunidades de Prática (CoPs), na perspectiva do conceito de Inteligência Coletiva de Pierre Lèvy. Descreve o ponto de vista de Lèvy, procurando estabelecer um diálogo como conceito de CoPs, criado por Etienne Wenger. Aponta os elementos encontrados nos fóruns virtuais e presenciais realizados pelo do Grupo Bibliocontas, (grupo formado por profissionais da informação que atuam nos Tribunais de Contas brasileiros), que podem contribuir para constituição de uma comunidade de prática. Verifica que os eventos/fóruns são canais integradores para efetivação de uma comunidade de prática, cujo resultado propicia a transformação das pessoas, a formação de identidades e a negociação de significados do fazer profissional. Observa que a construção coletiva de conhecimentos tem sido materializada na forma de diretrizes e ações, que foram ou estão para serem concretizadas pelas instituições dos participantes do grupo em questão, além do 
resultado da análise dos dados quantitativos, que indica um crescimento constante de troca de mensagens em ambiente virtual e aumento do número de participantes no grupo.

Palavras-Chaves: Comunidades de Prática; Inteligência Coletiva; Bibliocontas

\section{The contributions related to the use of conventions/forums in the constitution communities of practice and expression of the collective intelligence: the case of Bibliocontas}

This paper reflects on the Communities of Practice (CoPs) under the perspective provided by Pierre Lèvy's concept of Collective Intelligence. It describes Lèvy's viewpoint, with the intention to establish a dialogue with the concept of the CoPs created by Etienne Wenger. It points out some elements found in conventions/forums, of the Bibliocontas Group (a group formed by information professionals who function in the Brazilian Court of Auditors), that could contribute for the creation of communities of practice. It notes that the conventions/forums are channels of integration for the effectivity of a community of practice whose result promotes the transformation of people, the formation of identities, and the negotiation of meanings for the professional activity. It observes that the collective construction of knowledge has been materialized in the form of directives and actions that have been or are to be implemented by the institutions to which the participants of the group in question, and the result of analysis of quantitave data that indicates a steady growth of messaging in the virtual environment and increase the number of participants in the group.

Keywords: Communities of Practice; Collective Intelligence; Bibliocontas.

Recebido 13.10.2010 Aceito em 04.05.2012 


\section{Introdução}

O crescimento das redes e mesmo a popularização e aceitação da Internet, demonstram a importância ao acesso e troca de informação para construção de um conhecimento coletivo, fruto de um processo, denominado por Lèvy (1999), como Inteligência Coletiva. Nesse contexto, é possível verificar a criação de inúmeros grupos ou comunidades que, também, por meio da tecnologia, congregam indivíduos com interesses comuns e estes, por sua vez, encontram espaço na Internet para expor e debater suas ideias. Mediante esse processo interativo, conhecimentos são revistos, construídos e reconstruídos coletivamente, a partir dos diálogos que ocorrem dentro destas comunidades.

Diante do exposto, a discussão sobre o conceito de Comunidades de Prática (CoPs) torna-se oportuna, uma vez que elas se referem à construção coletiva de conhecimento. Tal acepção é defendida por Etienne Wenger, responsável por cunhar o conceito de CoPs, como, também, considerado o principal teórico desse campo de estudos. Sendo assim, pretende-se refletir sobre a interação entre membros de determinado grupo, decorrente do uso social dos recursos tecnológicos no processo de constituição das CoPs. Considera-se, deste modo, que as CoPs podem ser tratadas como reflexo dessa nova forma de sociabilidade contemporânea, descrita por Pierre Lèvy, os conceitos de comunidades virtuais e comunidades virtuais de prática que são vistos como desdobramentos das relações entre grupos específicos, por meio da tecnologia. A própria existência de tais conceitos reforça a hipótese defendida aqui, de que o compartilhamento e as interações ocorridas nos encontros virtuais ou presenciais contribuem para o desenvolvimento de práticas coletivas no interior das CoPs e, com efeito, para constituição destas comunidades.

Com a finalidade de evidenciar elementos referentes ao modo pelo qual ocorrem os diálogos de uma comunidade específica, optou-se, como metodologia de pesquisa, pela análise de um estudo de caso. O grupo Bibliocontas foi o objeto de estudo eleito, pois a forma de comunicação entre seus membros se dá através de fóruns virtuais e presenciais. 0 grupo em questão é composto por profissionais da informação, a maior parte por bibliotecários e arquivistas, ligados aos Tribunais de Contas (TCs) do Brasil. Na análise dos dados relacionados à interação do grupo, prevaleceu o enfoque quantitativo, uma vez que se almeja buscar evidências sobre a contribuição relativa ao uso de eventos/fóruns virtuais e presenciais para o exercício da inteligência coletiva dentro das CoPs.

\section{Inteligência coletiva}

A solidez da Ciência, assistida no século XIX, passou por um processo de questionamento ao longo do século $X X$, durante o qual a Ciência viveu um momento paradoxal: o mesmo conhecimento que dera amplitude ao rápido desenvolvimento de aparatos tecnológicos passou a 
ser confrontado pela capacidade de compreensão trazida no bojo do próprio desenvolvimento científico (CARDOSO, 1996, p. 65-66).

Neste contexto, a "metamorfose técnica do coletivo humano" (LÈVY, 1996, p. 10) nunca foi tão evidente, em função das mudanças rápidas e desestabilizantes. Surgem, segundo o autor, novas maneiras de pensar e de conviver e, ainda, as relações entre os homens, o trabalho e a própria inteligência dependem da elaboração incessante de diversos dispositivos informacionais e tecnológicos.

Hoje, conforme Lèvy (1999), a Sociedade da Informação traz à tona um projeto coletivo para o exercício de um novo humanismo, de modo a sugerir a hipótese da emergência de um novo espaço antropológico. As categorias fundamentais de gestão social do conhecimento, entendidas pela sucessão da oralidade, da escrita e da informática, "provocaram uma complexificação e deslocamento de centros de gravidade" (LÈVY, 1996, p. 10). A reconfiguração do saber e, consequentemente, das ecologias cognitivas, alteram a percepção dos sujeitos com relação ao real. No entanto, segundo Lèvy (1996), ao invés de profetizar uma catástrofe cultural, devido à proliferação da informatização, é preciso criar alternativas que articulem os gêneros do conhecimento e as novas tecnologias intelectuais.

O autor também destaca o papel fundamental dos diferentes agentes sociais que compõem a sociedade contemporânea. Para ele, a inteligência e o saber coletivo comandam os demais espaços, uma vez que considera que o "guia é o pensamento no interior do indivíduo, o intelectual coletivo entre os homens divididos" (LÈVY, 1999, p. 202). O intelectual coletivo ocuparia este espaço, porque, "desdobrando-se em um plano de imanência infinito, sem apropriação, sem inércia, é próprio dele deixar coexistir, acolher o ser em sua diversidade" (LÈVY, 1999, p. 202). Pelo fato de evoluir no interior do conhecimento e na invenção, "não tem nada a defender, nada a vender" (LÈVY, 1999, p. 202). Ao contrário: "todo seu esforço é acolher, tornar-se disponível, compreender, reinventar seu próprio tornar-se pensante. Neste sentido, o intelectual coletivo trabalha [...] a abertura, a humildade, as únicas coisas que permitem o aprendizado e o pensamento" (LÈVY, 1999, p. 202).

A inteligência coletiva, entendida por Lèvy não só como um conceito exclusivamente cognitivo, mas como um trabalho em comum acordo, 0 qual se baseia na "renovação do laço social por intermédio do conhecimento e o da inteligência coletiva propriamente dita" (LÉVY, 1999, p. 26). Em um coletivo inteligente, a comunidade assumiria, como objetivo, a negociação permanente da ordem estabelecida, de sua linguagem, do papel de cada um, o discernimento e a definição de seus objetos, a reinterpretação de sua memória. Este seria o processo de crescimento, de diferenciação e de retomada recíproca das singularidades, valorizando ao máximo a diversidade das qualidades humanas (LÉVY, 2002 apud FREIRE, 2005, p. 135-136). 
Neste sentido, o autor destaca a urgência da democratização ao acesso às tecnologias de informação e comunicação, a fim de proporcionar à coletividade o meio de proferir um discurso plural, sem a obrigação de passar por representantes (LÈVY, 2002 apud FREIRE, 2005, p. 138), sendo esta a grande reinvenção do conceito de democracia, ou o que o autor chama de "tecnodemocracia".

A pós-modernidade advertiu a sociedade contra a impossibilidade de se institucionalizar a verdade e uniformizar comportamentos. Ainda, demonstrou que o pensamento lógico e a capacidade analítica são atributos necessários, por exemplo, para um cientista, mas estão longe de serem únicos requisitos fundamentais. A intuição e os processos criativos, os quais atuam no nível subconsciente, também são peças estratégicas dentro deste desenvolvimento, contribuindo, inclusive, com o processo de criação de conhecimento.

Seguindo esta linha de pensamento, mas trazendo a discussão para o campo das organizações, Takeuchi e Nonaka (2008) sustentam a existência de dois tipos de conhecimento: o conhecimento explícito, relacionado ao que pode ser articulado na linguagem formal, facilmente transmitido, sistematizado e comunicado, e o conhecimento tácito, difícil de ser articulado na linguagem formal, é o conhecimento pessoal incorporado à experiência individual e envolve fatores intangíveis como, por exemplo, crenças pessoais, perspectivas, sistema de valor, insights, intuições, emoções e habilidades. A Gestão do Conhecimento foi o nome dado ao campo de estudos que abarca as teorias e as práticas desenvolvidas para o uso, tratamento, compartilhamento e gerenciamento do conhecimento em prol das organizações.

As CoPs são vistas, aqui, como um exemplo de gestão social do conhecimento, ou seja, um recurso para democratização e gerenciamento do conhecimento pelo e para coletivo. Por isso, elas são identificadas como uma importante estratégia para qualquer organização, principalmente aquelas que estão cientes acerca da importância do conhecimento. Neste sentido, as CoPs são apontadas como impulsionadoras do processo de criação do conhecimento (SCHELESINGER et al., 2008, p. 25).

\section{Comunidades de prática}

O antropólogo Etienne Wenger, além de pioneiro nos estudos sobre as CoPs, é considerado seu maior expoente. Os estudos posteriores que discutem aspectos relacionados tanto à teoria quanto à implementação das comunidades, referenciam o trabalho do pesquisador.

A descrição do conceito, trazida por Wenger (1991), consiste em um grupo de pessoas que juntas buscam conhecimento e dividem seu aprendizado coletivamente, procurando benefícios mútuos, sejam eles de curto ou longo prazo. Inicialmente, o termo era utilizado para caracterizar a troca entre alunos e professor. Mais tarde, Wenger expandiu seu uso, atribuindo às trocas entre grupos de outros gêneros. Isto tornou as 
análises mais complexas, pois passou a abarcar trocas em contextos com dinâmicas diferentes e assistemáticas (SILVA, 2004).

Tais comunidades se constituem a partir das relações interpessoais ocorridas no dia a dia. Embora tenham uma origem informal, sem nome e sem um foco explícito (WENGER, 1998 apud SILVA, 2004), seus participantes têm consciência dos objetivos da comunidade e de sua importância. Aliás, as CoPs, defendem Lave e Wenger (1991), são a própria condição intrínseca para a existência do conhecimento, pressupondo que o conhecimento se trata de um processo social. $O$ objetivo dessas comunidades é o de coexistir junto à estrutura formal, gerando suas próprias normas, valores, padrões e interações (SILVA, 2004).

A efetividade de uma CoP depende da força de três pilares: domínio, comunidade e prática (SNYDER; WENGER; BRIGGS, 2003). Domínio refere-se ao foco dos assuntos e ao quanto os membros se identificam com o tópico; comunidade inclui o relacionamento dos membros e a natureza das interações entre eles; prática consiste no repertório de ferramentas, métodos e habilidades e o próprio "fazer" dentro de um contexto específico (WENGER, 2007).

A participação das pessoas é voluntária, e os participantes podem ou não fazer parte da mesma organização. Ou, nas palavras de Terra (2001, p.137), as CoPs "ultrapassam os limites organizacionais" e são criadas naturalmente pela necessidade de compartilhar conhecimentos em comum (BEJARANO et al., 2005). Assim, caracterizam-se por serem essencialmente informais, mas isso não quer dizer que não sejam organizadas e, também, não devem ser confundidas com networks informais ou comunidades de interesse, pois estas servem apenas para distribuir informação (WENGER; MCDERMOTT; SNYDER, 2002).

Para Wenger (1991), as CoPs estão, cada vez mais, difundindo-se, porque provêem suporte ao aprendizado colaborativo e compartilhado. E nelas que cada um de seus membros encontra espaço para expressar seus anseios, ideias e contribuições para a preocupação coletiva que move a comunidade. Os membros não são guiados por uma instituição, eles se mantêm alinhados nesse tipo de organização com formas sutis de identificação que derivam do engajamento com o mundo e entre eles. Justamente, o diferencial reside nesta noção, na habilidade do individuo em interagir com seus grupos de interesse. Neste sentido, valoriza-se o engajamento dos profissionais nos processos de aprendizado e criação de conhecimento, e as CoPs realizam muito bem esse papel, trazendo um novo modelo de aprendizado.

Wenger (1991) defende que a alta administração deve incentivar as iniciativas das CoPs, e não impor sua criação, pois as comunidades são desenvolvidas, baseadas em relações de confiança. No entanto, a direção da empresa precisa estar inteirada sobre qual estágio de desenvolvimento a comunidade se encontra e ações específicas que devam tomar para dar apoio a ela; este apoio empresarial resume-se em facilitar a infraestrutura 
e as conexões entre os membros. Além de promover e divulgar os resultados práticos conseguidos por meio da rede e valorizar a participação e iniciativa individual (TERRA, 2001, p. 137).

O valor de uma comunidade, com relação ao retorno sobre investimento, manifesta-se no exterior dela, e não seu interior, isto é, para avaliar uma comunidade é necessário que se siga seu histórico de conhecimento, gerado por uma perspectiva externa (WENGER, 1991). Portanto, as organizações devem focar-se no levantamento de resultados promovidos pelas CoPs.

Terra e Gordon (2002) também dão destaque às contribuições da utilização das CoPs nas organizações: ajudam a dirigir a estratégia; dão inicio a novas linhas de negócio; resolvem problemas rapidamente; transferem as melhores práticas; desenvolvem habilidades profissionais; ajudam a companhia a recrutar e reter talentos; ganham novos negócios mais rapidamente; ajudam a servir melhor os atuais clientes; ajudam a desenvolver relacionamentos mais fortes com clientes; reduzem as barreiras culturais entre áreas funcionais e localidades distintas; desempenham um papel em atividades de fusão e aquisição; melhoram o capital social da organização; e ajudam a reduzir custos.

Além das contribuições dentro da própria organização, os autores apontam benefícios adquiridos pelos colaboradores: aprender com especialistas e colegas; desenvolver uma sensação de identidade e de fazer parte de algo importante; melhorar os elos com colegas de outros locais e organizações; desenvolver perspectiva mais ampla da organização e do ambiente; desenvolver redes pessoais de longo prazo; receber reconhecimento por habilidades e conhecimentos específicos, não diretamente relacionados à descrição formal do próprio cargo; melhora a autoestima; novos funcionários podem identificar rapidamente as principais fontes de conhecimento, acionistas importantes e atuais prioridades organizacionais; e oferecem o espaço ideal para a autorrealização e a busca de paixões pessoais (TERRA; GORDON, 2002).

Wenger (1998) define, ainda, três dimensões de relações, pelas quais a prática é a fonte de coerência de uma CoP: o engajamento mútuo, o repertório compartilhado e o empreendimento conjunto. O engajamento mútuo considera a diversidade de competências, o que cada um sabe e faz e como cada um se conecta ao conhecimento e às ações dos demais membros, que são complementares as suas ações. Segundo o autor, o que torna este engajamento possível é muito mais uma questão de diversidade do que de homogeneidade entre seus membros. 0 empreendimento conjunto está relacionado ao contexto histórico, social, cultural e institucional, levando consigo todas as vantagens e desvantagens desses contextos. As condições, os recursos, as demandas que dão forma à prática, são negociadas na comunidade. Uma vez que a CoP está sempre negociando seu empreendimento, as forças externas não têm impacto direto sobre a produção (WENGER, 1998, p. 77-82). O repertório compartilhado é um conjunto de recursos, artefatos, símbolos, 
rotinas, palavras, ações, conceitos, maneiras de fazer certas coisas e gestos produzidos e desenvolvidos pela comunidade ao longo de sua constituição e existência. Estes elementos ganham coerência como parte da prática de uma comunidade que compartilha um empreendimento e refletem uma história de mútuo engajamento (WENGER, 1998). Ele inclui os discursos e estilos. Pelos discursos, os membros criam e declaram o significado sobre o mundo; pelos estilos eles expressam suas formas de relacionamentos e suas identidades como membros. Todo o repertório deve ser produzido dentro da CoP.

A implementação e a consolidação de comunidades de prática são norteadas por princípios, como a existência de um projeto para a evolução da comunidade (expansão, maturação); a abertura para o diálogo com diferentes perspectivas (identificar o potencial para o desenvolvimento e a troca de conhecimento e as competências dos seus membros); incentivo aos diferentes níveis de participação (coordenador que organiza os eventos e conecta os membros; um grupo de pessoas ativamente participantes em discussões, debates e fóruns da comunidade); estabelecimento do foco no valor (importância para a organização); combinação de familiaridade e animação (encontros informais, reuniões, fóruns, teleconferências e o uso de web site, entre outras atividades); e criação de um ritmo para a comunidade (as suas interações e atividades dão ritmo e sustentação) (WENGER, 2002, p. 49-64). A gradual adoção destes princípios, segundo o autor, podem revelar estágios de amadurecimento do grupo, pois cada um dos princípios demonstra ações e valores ligados a aspectos relacionados à evolução das CoPs.

\section{Comunidades virtuais}

As tecnologias modificam algumas dimensões da inter-relação do indivíduo com o mundo, da percepção da realidade, da interação do tempo com o espaço. O desenvolvimento dos meios de comunicação cria novas formas de interação e novos tipos de relacionamento sociais. Neste contexto, a interação se dissocia do ambiente físico, de tal maneira que os indivíduos podem interagir ainda que não compartilhem do mesmo ambiente espaço-temporal (THOMPSON, 2002).

A discussão sobre as novas formas de relacionamento propiciadas pelo desenvolvimento das tecnologias de comunicação e de informação não é mais uma novidade. A ideia tradicional de comunidades, atualmente, é revista na forma de comunidades virtuais como resultado do incremento de acesso às formas de comunicação e interação no mundo online (PILLER et al., 2005).

A Internet tem possibilitado às pessoas de todo 0 mundo, desprezando limitações geográficas e de tempo, encontrar outras pessoas e reunir-se em grupos, com base na ampla rede de interesses culturais e afiliações sociais. Uma vez que uma pessoa se conecte e interaja com outras online, é mais provável que ela se torne membro recorrente de uma ou mais dessas reuniões, tornando-as uma fonte de informação e 
interação social (FONSECA et al., 2008). Rheingold (1993) foi quem primeiramente cunhou a expressão comunidade virtual, definindo-a como uma agregação social em que ocorrem discussões públicas (com certa duração), com sentimentos humanos suficientes, para formar teias (webs) de relacionamentos pessoais no cyber-espaço. Lévy afirmou que "uma comunidade virtual é constituída sobre as afinidades de interesses, de conhecimento, sobre projetos mútuos, em um processo de cooperação ou de troca, tudo isso independente das proximidades geográficas e das filiações institucionais" (LEVY, 1999, p. 127).

A maioria das comunidades virtuais é organizada em torno de interesses distintos, os quais podem estar relacionados a um tópico particular, produto ou até atributo demográfico. Ridings, Gefen e Arinze (2002, p. 273) oferecem a seguinte definição: "grupos de pessoas com interesses e práticas em comum que se comunicam regularmente, por um período de tempo determinado, de uma forma organizada na Internet, utilizando um mecanismo específico".

A definição acima se aproxima da definição de comunidades de prática de Wenger: "um grupo de pessoas que compartilham as mesmas práticas, interesses, objetivos de trabalho, paixão por alguma coisa que elas fazem e aprendem como fazer melhor interagindo regularmente" (WENGER; MCDERMOTT; SNYDER, 2002). Outra similaridade encontrada nos estudos de comunidades de prática e comunidades virtuais são os fatores que influenciam em sua formação. As comunidades virtuais, assim como as de prática, também necessitam do estabelecimento de um senso de comunidade para sua efetiva formação. Sarason (1974 apud GONGLA; RIZZUTO, 2001) descreve como os principais elementos das comunidades em geral: a percepção de similaridade entre os membros; o reconhecimento por parte dos membros da existência de uma interdependência; e os membros sentirem-se parte de uma estrutura estável e confiável. Fatores que são ressaltados por Wenger (2002) ao analisar as comunidades de prática, sua formação e operação. Porém, o que diferencia as CoPs das comunidades virtuais é o desenvolvimento de uma prática que a primeira realiza. Vale lembrar que as comunidades de prática são constituídas por elementos fundamentais: o domínio, a comunidade, a prática, a identidade, participação e a reificação.

Para Lévy (1999) as redes virtuais são ambientes propícios para estimular a construção de novos saberes. Neste contexto, as comunidades virtuais são constituídas, principalmente, pelas relações de colaboração e cooperação entre os membros dos grupos que a compõem. São as relações de colaboração e cooperação que mantêm as comunidades virtuais vivas. Enquanto existirem tais relações, as comunidades sobreviverão, podendo, inclusive gerar novas comunidades (TAJRA, 2002, p. 43). Para que, de fato, as comunidades virtuais exerçam seu papel, é necessário que as relações de colaboração e cooperação sejam desenvolvidas em ambientes democráticos, respeitando a participação de todos, compartilhando valores, crenças e utilizando regras estabelecidas em comum acordo com os membros do grupo. 
A interação realizada a partir das comunidades virtuais é caracterizada não apenas pelas mensagens trocadas (o conteúdo) e pelos integrantes da rede que se encontram em contextos geográfico, social, político e temporal diferentes. Esta interação é caracterizada, também, pelo relacionamento que existe entre os integrantes. Trata-se de uma construção coletiva, inventada pelos indivíduos que agem durante o processo, que não pode ser manipulada unilateralmente e nem prédeterminada (PRIMO, 2007).

Essas interações foram impulsionadas pela Web 2.0, termo utilizado para descrever a segunda geração da internet, é uma tendência que reforça o conceito de troca de informações e colaboração dos internautas com sites e serviços virtuais. Tim Berners-Lee, criador da Word Wide Web, argumenta que a internet foi concebida como um canal de comunicação aberto e que a Web 2.0 é só mais um jargão sem sentido (TERRA, 2009).

A Web 2.0, embora ainda seja predominantemente um fenômeno da Internet aberta, já é vista por organizações líderes como uma ferramenta corporativa com muitas aplicações. Nos últimos anos, executivos de diversas empresas começaram a perceber que essas ferramentas e esses conceitos podem transformar a maneira como as empresas se organizam e são geridas. Empresas que já utilizam essas ferramentas estão sendo caracterizadas, por especialistas da área, como empresas mais transparentes, colaborativas e com processo de comunicação muito mais efetivo entre as diferentes pessoas dentro das organizações e, até mesmo, entre as organizações e seus stakeholders (TERRA, 2009).

O crescimento em progressão geométrica do número de blogs é uma recorrente ilustração da $W e b$ 2.0. Pelos blogs, pequenas redes de amigos ou de grupos de interessados em nichos muito específicos podem interagir. Já a interconexão entre esses grupos pode gerar significativos efeitos em rede. Logo, hoje, na $W e b$, não apenas os grandes portais têm importância. Mesmo os blogs que reúnem pequenos grupos com interesses segmentados ganham peso na rede a partir de sua interconexão com outros subsistemas. Ou seja, o modelo informacional de um grande centro distribuidor de mensagens passa a competir com a lógica sistêmica da conexão de micro-redes. Em outras palavras, enquanto modelo massivo foca-se no centro, a Web 2.0 fortalece as bordas das redes (PRIMO, 2007).

O potencial das redes de relacionamento, uma das marcas da Web 2.0, é muito grande. Essas redes possibilitam o estudo em grupo, a troca de informações, a divulgação dos mais diversos conteúdos informacionais, por meio de mecanismos para comunicação com outros usuários, tais como blogs, microblogs, wikis, fóruns, chats, emails ou mensagens instantâneas. Permite, também, identificar pessoas que possuem interesses comuns e assim criar uma rede de aprendizado, de transmissão de conhecimento, divulgação de conteúdos das mais diversas áreas (LUVIZOTTO; VIDOTTI, 2010). 


\section{Comunidades de prática virtuais}

A mesma teoria que sustenta as CoPs presenciais é utilizada para o modelo de CoPs virtuais, ou seja, grande parte da aprendizagem dos profissionais acontece de maneira informal, compartilhando experiências, conhecimentos e soluções de problemas uns com os outros. Esse tipo de aprendizagem é facilitado pelos recursos disponíveis na Internet, onde o conceito de ferramentas colaborativas é uma tendência que reforça a troca de informações e colaboração dos usuários com sítios e serviços virtuais (O'REILLY, 2005).

Essa característica social da Internet aponta para o potencial das comunidades em rede, nas quais a inteligência coletiva é identificada como potencialmente transformadora para os negócios. Neste contexto, as CoPs podem ser vistas como estímulos ao aprendizado organizacional.

Recentemente, as fronteiras relacionadas ao conceito de CoPs sofreram modificações significativas. O surgimento crescente de redes de conhecimento similares às CoPs que, entretanto, ultrapassam as fronteiras organizacionais, como uma comunidade relacionada a uma atividade profissional, por exemplo. A emergência destas comunidades extraorganizacionais focadas na prática, frequentemente acontece em áreas, nas quais o ritmo das mudanças tecnológicas exige acesso a conhecimentos e recursos que não são encontrados no interior de uma única organização (CORREIA, 2007).

Neste sentido, as tecnologias de comunicação mediadas por computador oferecem uma alternativa aos limites geográficos e de tempo associados aos encontros face a face, originando novas estruturas no ciberespaço que, segundo Castells (1996; 2003) assemelham-se a comunidades em que a interação social é eletrônica e a Internet é o meio utilizado para as trocas.

No entanto, Wenger, McDermott e Snyder (2002) levantam várias preocupações sobre CoPs virtuais, como a distância entre os membros, tamanho da comunidade (quantidade de pessoas), afiliações (e.g. membros da comunidade trabalharem com competidores), diferenças culturais (e.g. linguagem e valores), dificuldade de conciliar muitos interesses diferentes, estabelecimento de confiança e intimidade durante a prática (craft intimacy). Também oferecem princípios de projeto de CoPs virtuais, de modo a lidar com esses problemas: conseguir o alinhamento dos interessados, criar uma estrutura que promova variações locais e conexões globais, estabelecer um ritmo para a comunidade e espaços privados para interação entre as pessoas de modo mais sistemático (WENGER; McDERMOTT; SNYDER, 2002, p. 113-137).

Ao analisar os vários fatores que caracterizam as CoPs, em seu sentido clássico, e compará-los, sob o ponto de vista de uma comunidade virtual, identifica-se que a colaboração entre os membros altera a dinâmica do grupo, contribuindo para elevar o conteúdo abordado, o 
conceito de coordenação e liderança, a forma de aprender, a necessidade de novas ferramentas de colaboração, bem como a definição de tempo e espaço de trabalho apropriados e comportamento do grupo. Assim, considera-se que os fóruns (presenciais ou virtuais) são elementos facilitadores para a colaboração, interação e efetivação de CoPs.

\section{0 caso do Bibliocontas}

Com o objetivo de trocar experiências e, assim, compartilhar conhecimento, em 2003, a então gestora da Unidade de Informação (UI) do TC de Pernambuco, Roseane Britto e a bibliotecária Sandra de Souza Ferreira Maia, espontaneamente tiveram a iniciativa de entrar em contato com as demais UIs dos TCs do Brasil.

Em um primeiro momento, tendo em vista a inexistência de contatos anteriores e mesmo sequer de dados como nome dos responsáveis, localização, acervo, recursos e infraestrutura, finalidades das UIs e a necessidade de cooperação e integração para estabelecimento de parcerias, a UI do TCE/PE organizou, com o aval dos demais responsáveis pelas UIs, dos TC o I Fórum Nacional dos Bibliotecários dos TCs, em outubro de 2003, evento presencial.

O referido evento, além de contar com a presença de representantes de dez TCs, incluindo bibliotecários e gestores das UIs, contou com a participação de outras instituições jurídicas de Pernambuco, totalizando 38 participantes.

De acordo com o relatório do evento, as unidades participantes buscaram a interação com as diretrizes estratégicas assumidas pelos TCs, seguindo suas linhas de ação, especialmente, as consignadas no programa de desenvolvimento e suporte institucional, tais como: 1) utilizar métodos e tecnologias modernas visando atingir um melhor nível qualitativo nas informações fornecidas; 2) aperfeiçoar e consolidar o uso de tecnologias de informação e comunicação pelo corpo técnico; 3) buscar maior integração com as UIs de outros Tribunais; 4) avaliar a relação custo/benefício, com vistas a otimização dos recursos destinados à Biblioteca; e 5) incentivar a valorização, motivação e aprimoramento técnico-profissional das pessoas que integram a equipe (FóRUM NACIONAL DOS BIBLIOTECÁRIOS DOS TRIBUNAIS DE CONTAS, 2003, p. 3).

Para tanto, o Fórum constituiu-se como um elemento de integração, reunindo os bibliotecários dos vários TCs do país e de instituições do segmento jurídico de Pernambuco, para discutir suas realidades - semelhantes e distintas -, criar mecanismos de cooperação de informações, nos mais variados âmbitos e, estabelecer metas e compromissos para as UIs, em comum acordo com as realidades de cada uma (FÓRUM NACIONAL DOS BIBLIOTECÁRIOS DOS TRIBUNAIS DE CONTAS, 2003, p. 4).

Como resultado do primeiro encontro, foi elaborado um quadro comparativo das UIs com informações quanto ao organograma, 
infraestrutura e organização, recursos humanos, acervo, estatísticas e tecnologias da informação utilizadas. Também foram elaborados Carta Compromisso e Protocolo de Intenções, os quais versam acerca dos pontos consensualmente traçados para cooperação entre as UIs. Entre eles, consta reivindicação de apoio dos TCs, para o estabelecimento de uniformização de dotação orçamentária para as UIs, a realização de compartilhamento de base de dados de conteúdos tanto doutrinários quanto jurisprudenciais, via Internet, a criação de um portal e uma lista de discussões para facilitar a comunicação entre o grupo, como meio para buscar a valorização das UIs perante os TCs e a sociedade e promover a conscientização, motivação e capacitação dos membros da equipe.

Durante o próprio evento, já foi criada a lista de discussão www.grupos.com.br/group/bibliocontas, pela qual é realizada, até hoje, a maior parte da comunicação do grupo. Nesta lista, estão registradas todas as trocas de informações ocorridas e sua evolução desde 2003, conforme o Gráfico 1. Além de discutir coletivamente os pontos traçados no evento, há também trocas de informações diversificadas de serviços, projetos, eventos, lançamentos de publicações, pesquisas, legislação, jurisprudência, dúvidas, troca de ideias e experiências, opiniões, entre outras.

Dois anos depois, em outubro de 2005, foi realizado o II Fórum presencial, no Tribunal de Contas do Rio Grande do Sul, em Porto Alegre. O número de TCs participantes diminuiu de dez para nove e a quantidade de participantes do evento de 38 para doze, em relação ao primeiro evento, apesar do número de participantes da lista de discussão ter aumentado de 35 para 53, até contar com 137 participantes mais tarde, em 2008 (ver Gráfico 2). Também, o evento contou com a participação de mais duas instituições do segmento do Rio Grande do Sul.

Gráfico 1 - Quantidade relativa ao fluxo de mensagens do fórum virtual ${ }^{1}$ do Bibliocontas - 2003-2008

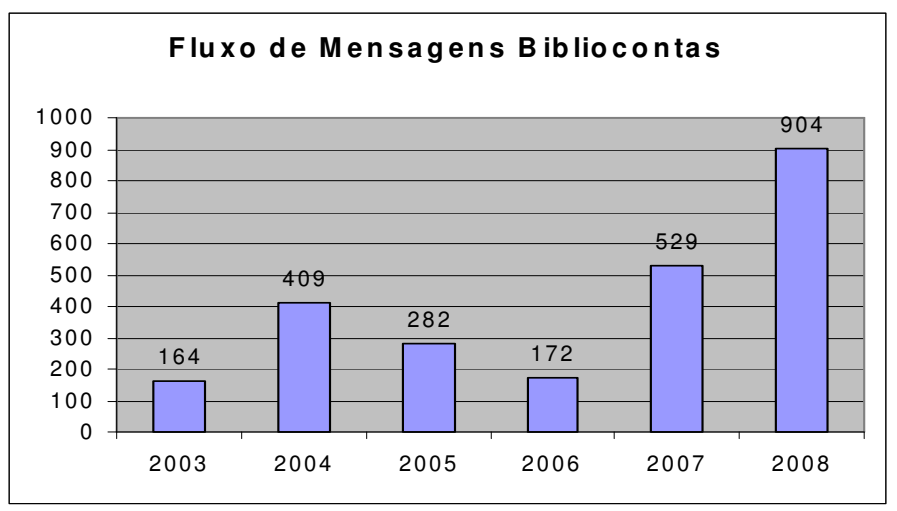

Fonte: Adaptado de BIBLIOCONTAS (2008).

\footnotetext{
${ }^{1}$ Fórum virtual é aqui tratado como sinônimo de lista de discussão.
} 
Gráfico 2 - Quantidade de participantes do fórum virtual do Bibliocontas 2003-2008

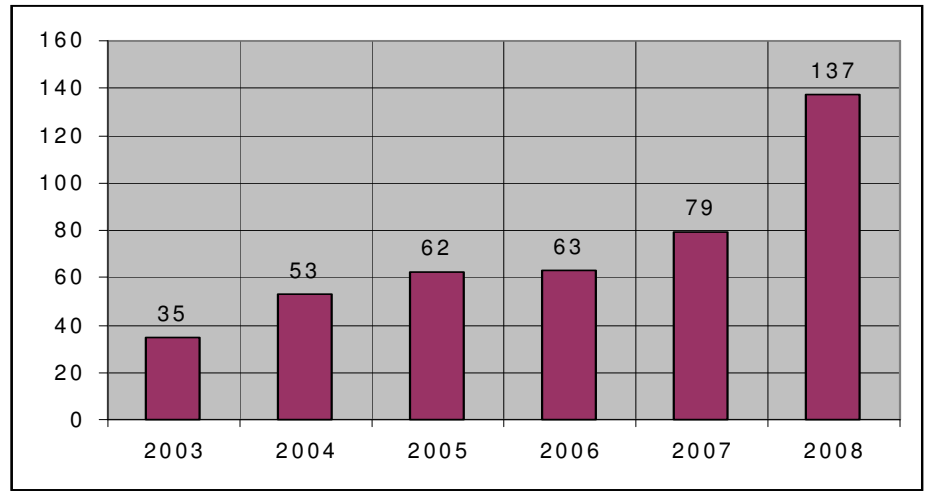

Fonte: Adaptado de BIBLIOCONTAS (2008).

Neste encontro, foi discutida principalmente a necessidade de aperfeiçoamento dos serviços prestados nas UIs do Sistema TC. A maior expectativa do Fórum presencial era que as atividades desenvolvidas pelas unidades estejam contempladas nos projetos do Programa de Modernização do Sistema de Controle Externo dos Estados e Municípios (PROMOEX), visando, desta forma, acompanhar as diretrizes do Programa (FÓRUM NACIONAL DOS BIBLIOTECÁRIOS DOS TRIBUNAIS DE CONTAS, 2005, p. 4). Outros que se destacaram foram: 1) apresentação, no próximo Congresso dos TCs do Brasil, de trabalho relativo sobre o Bibliocontas; 2) criação da logomarca do Bibliocontas; 3) necessidade de sensibilizar e incentivar os TCs para a importância da preservação de sua memória institucional; 4) criação da Biblioteca Virtual dos TCs; 5) elaboração de um guia das Bibliotecas dos TCs a ser inserido no futuro portal do Bibliocontas; e 7) prosseguir na consolidação dos compromissos firmados no I Fórum (FÓRUM NACIONAL DOS BIBLIOTECÁRIOS DOS TRIBUNAIS DE CONTAS, 2005, p. 5).

Somente em março de 2008, se concretiza uma das metas firmadas no II Fórum: a publicação, pela Divisão de Biblioteca e Documentação do Tribunal de Contas do Município do Rio de Janeiro (TCM/RJ) do Guia de Bibliotecas dos Tribunais de Contas do Brasil. Os dados para composição da publicação foram fornecidos por todas as UIs participantes do Grupo Bibliocontas, via lista de discussões.

O III Fórum, realizado em junho de 2008, passou a se chamar Fórum Nacional de Bibliotecários e Arquivistas dos TCs, congregando, assim, mais uma categoria de profissional da informação. O evento foi promovido pelo Departamento de Informação e Documentação (DID, antigo DDB) do TCE/PE e, realizado em Recife. Contou com a participação de quatorze TCs - apesar de dezenove TCs já estarem presentes na lista de discussões - e outras Instituições de diversos segmentos do Estado de Pernambuco, totalizando 52 participantes.

Os objetivos do terceiro fórum presencial foram construídos, tendo como base a promoção de discussões acerca das realidades vivenciadas pelos profissionais da informação em seus contextos. Mais ainda, buscou 
fomentar e criar espaços, ferramentas e estratégias para a troca de experiências para os bibliotecários e arquivistas integrados na rede já conhecida como Bibliocontas (FÓRUM NACIONAL DOS BIBLIOTECÁRIOS E ARQUIVISTAS DOS TRIBUNAIS DE CONTAS, 2008, p. 5).

Como resultado do evento, foi elaborado um novo Protocolo de Intenções, no qual constam as seguintes metas delineadas pelo grupo: 1) viabilizar a criação do Portal Bibliocontas; 2) utilizar o Portal para as seguintes atividades: a) Base de Dados Referencial sobre Controle Externo; b) indexação cooperativa de artigos de periódicos em assuntos afetos aos campos de atuação dos Tribunais; e c) reunião e organização da jurisprudência dos TCs; 3) aprimorar o uso da lista de discussão: a) ampliar o número de participantes; b) solucionar problemas de recebimento e envio de mensagens; e c) utilizar palavras-chave no campo de assunto; d) responder às mensagens dos colegas solicitando informação, ainda que não haja resposta positiva; 4) inserir as UIs no planejamento estratégico das instituições, de forma a que possam utilizar os recursos do PROMOEX; 5) assegurar dotação orçamentária para as UIs; 6) participar dos programas de capacitação das instituições, em dois aspectos; 7) recomendar a aquisição de sistema de gerenciamento de acervos para Bibliotecas, Arquivos e Centros de Memória, ainda não informatizados, de forma a facilitar a formação de uma futura rede de intercâmbio de dados; 8) implementar o projeto Clube de Leitura nas Bibliotecas de todos os Tribunais; 9) incentivar a realização de campanhas de marketing dos Arquivos, Bibliotecas e Centros de Memória dos TCs; 10) ressaltar a importância da existência de campanhas de preservação e conservação de acervos; e, por último, 11) ampliar a abrangência do grupo Bibliocontas, para incluir as UIs das instituições do MERCOSUL.

Quatro meses após o último Fórum, a integrante do grupo e Gestora do Núcleo de Biblioteca e Documentação do TCE/CE, Regina Lúcia da Silva Braga, e a bibliotecária Teça Frota, ministraram palestra sobre o Bibliocontas, no VI Encontro do Colégio de Corregedores, evento paralelo ao Encontro Anual dos TCs do Brasil. Este fato trata-se de um marco para as UIs, pois é a primeira participação de um representante do grupo em um evento significante como este no âmbito dos TCs. Além disso, um dos principais propósitos do grupo, que é conscientização junto aos dirigentes dos TCs acerca da importância do acesso à informação e sua disseminação de forma eficiente promovida pelos Bibliotecários e Arquivistas, começa a ser atingido.

\section{As contribuições dos eventos/fóruns para a constituição de comunidades de prática}

As atividades do grupo Bibliocontas, relatadas acima, apontam para alguns elementos essenciais à constituição de CoPs. Dentre estes, destacam-se o engajamento, o repertório compartilhado, 0 empreendimento negociado, a identidade e o domínio. A efetivação de 
uma comunidade se dá pela prática fomentada pelo compartilhamento de conhecimento que ocorre nos encontros/fóruns.

Na perspectiva do engajamento, da imaginação, do alinhamento, da participação e da cooperação, os eventos/fóruns podem ser utilizados como fomentadores para o compartilhamento e criação do conhecimento nas CoPs. Acredita-se que podem contribuir como mediação no processo interativo entre os membros de uma comunidade de prática na realização de tarefas conjuntas, na negociação de significados e no compartilhamento de experiências e competências, em uma visão de histórias compartilhadas de aprendizagem.

Os eventos/fóruns são canais integradores importantes para efetivação de uma comunidade de prática, cujo resultado propicia a transformação das pessoas, a formação de identidades e a negociação de significados. As dimensões do aprendizado centradas nas facilidades de engajamento, ou seja, na facilitação de encontros entre os diversos domínios, de encontros virtuais ou presenciais, na produção de conhecimentos que tragam à tona o conhecimento criado a partir da prática. Neste sentido, os encontros do Bibliocontas ocorridos facilitaram a localização das pessoas no espaço e no tempo, por meio de diretrizes, relatos de trajetórias, criação de modelos e representações de padrões. Contribuíram, também, para as dimensões do aprendizado centradas nas facilidades de alinhamento, ou seja, para a criação de focos comuns, entendimentos compartilhados, criação de métodos, processos e procedimentos, práticas de fronteira e de negociadores. Os eventos/fóruns, como outras formas de partilhar informações e experiências são o embrião para a efetivação dos relacionamentos, da confiança e da identidade. O estudo de Duarte e outros ilustra o ponto de vista desta análise, quando coloca que "os casos aqui relatados, não implicaram, objetivamente, na construção de uma comunidade de prática. [...] a idéia de discutir assuntos relacionadas a duas bibliotecas universitárias, por meio de um evento denominado de Chá de Compartilhamento de Conhecimento, indicou a necessidade de se criar essa comunidade" (DUARTE et al., 2008, p. 6).

O organizador ou coordenador do evento e o líder de CoPs são as pessoas mais experientes à frente de um grupo. Ambos têm os recursos para motivar seus aprendizes ou até o "poder" para direcionar o grupo segundo seus objetivos. O organizador ou coordenador do evento aprende a conhecer além do que lhe é oferecido. Ele aprende a fazer, ensaia situações reais e que podem ajudá-lo a enfrentar situações de vida, de trabalho, de relacionamentos, dentre outras. Como um aprendiz de comunidades de prática, o organizador ou coordenador de eventos aprende a ser pela interpretação de diversos personagens, coloca-se em papéis diferentes, sabendo agir com autonomia, cooperação e interação com as demais pessoas do grupo. Dentro da visão de facilitação para criação do conhecimento nas organizações, os Eventos são uma possibilidade de se efetivar a troca ou compartilhamento de conhecimento para a constituição de comunidades de prática. 


\section{Considerações finais}

Para entender o caso Bibliocontas, além de fornecer explicações acerca da sua lógica de funcionamento, foi necessário entender este fenômeno não somente a partir dos teóricos que discorrem a respeito o conceito de CoPs, mas, sobretudo, a partir de uma perspectiva histórica, de modo a fundamentar: as relações do homem com a construção e a sistematização do conhecimento, tendo como ponto de partida a consolidação do discurso cientifico; e a dicotomia entre o sujeito (indivíduo) e o sujeito coletivo, dada pela transição entre Modernidade e Pós-modernidade, a qual determinou as formas de construção do conhecimento na contemporaneidade.

No campo teórico, o diálogo entre os conceitos de Inteligência Coletiva de Lèvy e de CoPs de Wenger mostra a convergência entre ambos. As CoPs favorecem a geração de conhecimento, a partir da transformação do conhecimento tácito ou individual em explícito ou coletivo, tornando-se espaço propício para o exercício e aprimoramento da Inteligência Coletiva. Entendida como um espaço essencialmente democrático, auxiliada pelas tecnologias de informação e comunicaçãos, as quais facilitam a troca de informações e as relações entre os indivíduos em prol do bem comum, elucida o conceito de tecnodemocracia de Lèvy. É inegável o impacto da tecnologia nos modos de sociabilidade, entretanto, destaca-se que o desenvolvimento de comunidades, nas quais se pratica a inteligência coletiva, não está obrigatoriamente atrelado ao uso da tecnologia. Considera-se que ela atua como um importante facilitador para interação entre os membros de uma comunidade, mas não como um elemento determinante para constituição delas.

Ao trazer a discussão para o campo empírico, percebeu-se que a dinâmica de eventos/fóruns utilizada pelo Bibliocontas contribui para constituição de CoPs. De fato, trata-se de um grupo de pessoas constituído informalmente com o intuito de acumular, agregar e compartilhar conhecimento, fundamentando a construção do conhecimento a partir do aprendizado coletivo.

A crescente valorização do sujeito coletivo é evidenciada pelo crescimento de grupos cujo propósito é a troca de informações e experiências. A dinâmica para o compartilhamento desses grupos de profissionais ocorre, normalmente, em encontros informais, como eventos e fóruns, tanto virtuais como presenciais. No caso analisado, observou-se o crescimento quantitativo do fluxo de comunicação na lista de discussão e o aumento da quantidade de participantes nos fóruns virtuais e presenciais do Bibliocontas. Tais resultados podem indicar que a construção coletiva de conhecimento, dentro da comunidade analisada, trata-se de uma prática constante e em crescimento e, deste modo, condizente com o contexto histórico-social vivenciado na contemporaneidade, conforme a percepção de Lèvy. 
O caso Bibliocontas demonstrou que a utilização de eventos/fóruns, como forma de compartilhamento,o pode auxiliar a constituição de CoPs possibilitando a criação coletiva de conhecimento com benefícios às organizações e aos membros do grupo. As limitações do trabalho se referem uma análise orientada para aspectos mais qualitativos cujo foco ficou restrito à descrição das atividades desenvolvidas e objetivos firmados nos encontros presenciais. Ressalta-se a necessidade de realização de estudos que visem análise do conteúdo das mensagens trocadas em ambientes virtuais para se identificar características mais específicas do grupo (domínio, identidade, engajamento, alinhamento) e da prática. A partir desses estudos é possível verificar o modo pelo qual uma comunidade pode ser virtualmente estruturada, e o modo pelo qual se dá as relações de interação, cooperação e troca entre os participantes, além dos encontros presenciais.

Finalmente, cabe ressaltar que a formação de CoPs é possibilitada, especialmente pelo incentivo aos diferentes níveis de participação; a abertura para o diálogo com diferentes perspectivas, ou seja, propiciar ao máximo o uso das competências individuais em prol do grupo; a combinação de familiaridade e animação (encontros informais, reuniões, fóruns, web site); e a criação de um ritmo que dá sustentação ao empreendimento (WENGER, 2002, p. 49-64). Pela análise do caso, é possível perceber a intenção do grupo, mas não há elementos conclusivos que indiquem as relações, as formas de engajamento e o alinhamento do grupo, conforme conceitos expostos por Wenger. Pelo relato, verifica-se que a construção coletiva de conhecimentos tem sido materializada na forma de diretrizes e ações que foram ou estão para serem concretizadas pelas instituições, além do crescimento quantitativo de troca de mensagens e do aumento de participantes tanto na lista de discussão virtual quanto nos fóruns presenciais.

\section{Referências}

BEJARANO, V. C. et al. Equipes e comunidades de prática como estruturas complementares na gestão do conhecimento organizacional. ENCONTRO NAC. DE ENG. DE PRODUÇÃO, 25. Porto Alegre, RS, Brasil, 29 out a $01 \mathrm{de}$ nov. de 2005. Anais... Porto Alegre, 2005.

CARDOSO, A. M. P. Pós-modernismo e informação: conceitos complementares? Perspectivas em Ciência da Informação. Belo Horizonte, v. 1, n. 1, 1996.

CASTELLS, M. A sociedade em rede. São Paulo: Paz e Terra, 1999.

CORREIA, M. P. L. Aprendizagem e compartilhamento de conhecimento em comunidades virtuais de prática: estudo de caso na comunidade virtual de desenvolvimento de software livre DEBIAN-BR-CDD. 2007. 215f. Dissertação (Mestrado em Administração) - Curso de PósGraduação em Administração, Escola de Administração, Universidade Federal da Bahia - UFBA, Salvador, 2007. 
DUARTE, E. N. et al. Aprendizagem organizacional em unidades de informação: do grupo focal à comunidade de prática. Perspect. Ciênc. Inf., v. 13, n. 3, p. 78-95, set./dez. 2008.

FONSECA, J. M. et al. Tendências sobre as comunidades virtuais da perspectiva dos prosumers. RAE-Eletrônica, v. 7, n. 2, artigo 24, jul./dez. 2008.

FÓRUM NACIONAL DE BIBLIOTECÁRIOS DOS TRIBUNAIS DE CONTAS, $1 .$, 2003, Recife. Relatório. Recife: TCE/PE, 2003.

FÓRUM NACIONAL DE BIBLIOTECÁRIOS DOS TRIBUNAIS DE CONTAS, 2., 2005, Porto Alegre. Relatório. Porto Alegre: TCE/RS, 2005.

FÓRUM NACIONAL DE BIBLIOTECÁRIOS E ARQUIVISTAS DOS TRIBUNAIS DE CONTAS, 3., 2008, Recife. Relatório. Recife: TCE/PE, 2008.

FREIRE, I. M. A utopia planetária de Pierre Lévy: uma leitura hipertextual d'inteligência coletiva. Perspectivas em Ciência da Informação, Belo Horizonte, v. 10, n. 2. 2005.

GONGLA, P; RIZZUTO, C. Evolving communities of practice: IBM global services experience. IBM systems journal, v. 40, n. 4, 2001.

BIBLIOCONTAS. Grupo de discussão sobre as realidades dos profissionais da informação, nas Bibliotecas dos Tribunais de Contas. Disponível em: <http://www.grupos.com.br/group/bibliocontas>. Acesso em: 15 ago. 2008 .

LAVE, J.; WENGER, E. Situated learning, legitimate peripheral participation. Cambridge: University Press, 1991.

LÉVY, P. A inteligência coletiva: por uma antropologia do ciberespaço. São Paulo: Loyola, 1999.

LÉVY, P. As tecnologias da inteligência: o futuro do pensamento na era da informática. São Paulo: Editora 34, 1996.

LÉVY, P. A inteligência coletiva: por uma antropologia do ciberespaço. 3. ed. São Paulo: Loyola, 2002 apud FREIRE, I. M. A utopia planetária de Pierre Lévy: uma leitura hipertextual d'inteligência coletiva. Perspectivas em Ciência da Informação, Belo Horizonte, v. 10, n. 2. 2005.

LUVIZOTTO,C. K. ; VIDOTTI, S. A. B. G. Redes sociais e comunidades virtuais para a preservação e transmissão das tradições gaúchas na Internet. Informação \& Sociedade: Estudos, João Pessoa, v. 20, n. 2, p. 77-88, maio/ago. 2010.

O'REILLY, T. What is Web 2.0: design patterns and business models for the next generation of software. 2005. Disponível em: <http://oreilly.com/web2/archive/what-is-web-20.html> Acesso em: 15 jul. 2010.

PILLER, F. et al. Overcoming mass confusion: collaborative customer codesign in online communities. Journal of Computer-Mediated Communication, v. 10, n. 4, jul. 2005. 
PRIMO, A. O aspecto relacional das interações na Web 2.0. E- Compós, Brasília, v. 9, 2007.

RHEINGOLD, H. The virtual community. Reading, MA: Addison-Wesley, 1993.

RIDINGS, C; GEFEN, D; ARINZE, B. Some antecedents and effects of trust in virtual communities. Journal of Strategic Information Systems, v. 11, $\mathrm{n}$. 3-4, p. 271-29, 2002.

SARASON, S. B. The psychological sense of community: prospects for a community psychology. San Francisco: Jossey-Bass Publishers,1974 apud GONGLA, P; RIZZUTO, C. Evolving communities of practice: IBM global services experience. IBM systems journal, v. 40, n. 4, 2001.

RIO DE JANEIRO (Município). Tribunal de Contas do Município. Guia de bibliotecas dos Tribunais de Contas do Brasil. Rio de Janeiro: TCM/RJ, 2008.

SCHLESINGER, C. C. B. et al. Gestão do conhecimento na administração pública. Curitiba: IMAP, 2008.

SILVA, H. F. N. Criação e compartilhamento de conhecimento em comunidades de prática: uma proposta metodológica. $216 \mathrm{f}$. Tese (Doutorado em Engenharia da Produção) - Programa de Pós-Graduação em Engenharia de Produção do Departamento de Engenharia de Produção e Sistemas da Universidade Federal de Santa Catarina, Florianópolis, 2004

SNYDER, W; WENGER, E.; BRIGGS, X. S. Communities of practice in government: leveraging knowledge for performance. The Public Manager. v.32, n.4, p.17-22, 2003.

TAJRA, S. Comunidades virtuais: um fenômeno social autopoiético na sociedade do conhecimento. Dissertação (Mestrado). PUC/SP - Brasil, 2002. Disponível em: <www.tajratecnologias.com.br/ artigo4.htm>. Acesso em: 8 jun. 2010.

TAKEUCHI, H.; NONAKA, I. Gestão do conhecimento. Porto Alegre: Bookman, 2008.

TERRA, J. C. C. Comunidades de prática: conceitos, resultados e métodos de gestão. Disponível em:

<http://biblioteca.terraforum.com.br/BibliotecaArtigo/libdoc00000098v00 2Comunidades\%20de\%20Pratica-conceitos,\%20resultad.pdf $>$. Acesso em: 15 jul. 2010.

TERRA, J. C. C.; GORDON, C. Portais corporativos: a revolução na gestão do conhecimento. São Paulo: Negócio Editora, 2002.

TERRA, J. C. C. Gestão 2.0: como integrar a colaboração e a participação em massa para o sucesso nos negócios. Rio de Janeiro: Elsevier, 2009.

THOMPSON, J. B. A mídia e a modernidade. 5. ed. Petrópolis: Vozes, 2002. 
WENGER, E. Communities of practice: learning as a social system. The Systems Thinker, v. 9, n. 5, 1998.

WENGER, E. Communities of practice: where learning takes place. Benchmark Magazine, Fall issue, 1991.

WENGER, E.; MCDERMOTT, R.; SNYDER, W. Cultivating communities of practice: a guide to managing knowledge. Boston: Harvard Business, 2002.

WENGER, E. Communities of practice: a brief introduction - communities of practice, 2007. Disponível em: <http://www.ewenger.com/theory/>. Acesso em: 04 abr. 2012.

WENGER, E. Communities of practice: learning, meaning and identity. Cambridge: Cambridge University Press, 1998 apud SILVA, H. F. N. Criação e compartilhamento de conhecimento em comunidades de prática: uma proposta metodológica. 216 f. Tese (Doutorado em Engenharia da Produção) - Programa de Pós-Graduação em Engenharia de Produção do Departamento de Engenharia de Produção e Sistemas, Universidade Federal de Santa Catarina, Florianópolis, 2004. 